\title{
Comparison Of Expectations For Health Services Between Inpatients From Mental Health Department And Endocrinology Department In China
}

This article was published in the following Dove Press journal:

Patient Preference and Adherence

\author{
Qian Liu' \\ Wei Zhou (iD) ${ }^{1,2}$ \\ Lu Niu ${ }^{3}$ \\ $\mathrm{Yu} \mathrm{Yu}^{4}$ \\ Lizhang Chen ${ }^{1,2}$ \\ Bihua Luo ${ }^{5}$ \\ Shuiyuan Xiao ${ }^{1,2}$ \\ 'Xiangya School of Public Health, Central \\ South University, Changsha, Hunan, \\ People's Republic of China; ${ }^{2}$ Hospital \\ Administration Institute, Xiangya \\ Hospital, Central South University, \\ Changsha, Hunan, People's Republic of \\ China; ${ }^{3}$ Department of Social Psychiatry, \\ The Affiliated Brain Hospital of \\ Guangzhou Medical University \\ (Guangzhou Huiai Hospital), Guangzhou, \\ Guangdong, People's Republic of China; \\ ${ }^{4}$ Division of Prevention and Community \\ Research and the Consultation Center, \\ Yale School of Medicine, New Haven, CT, \\ USA; ${ }^{5}$ Department of Metabolism and \\ Endocrinology, Second Xiangya Hospital, \\ Central South University, Changsha, \\ Hunan, People's Republic of China
}

Correspondence: Wei Zhou; Shuiyuan Xiao Xiangya School of Public Health, Central South University, No. 87 Xiangya Street, Changsha, Hunan 410087, People's Republic of China

Tel/fax +86 73I 84805459

Email weizhou86@।63.com; xiaosy@csu.edu.cn
Background: Patient expectations for health services refer to the anticipation or the belief about what should be encountered in the healthcare system. Understanding patient expectations can improve patient satisfaction and healthcare compliance. It is particularly important for patients with mental disorders, as greater healthcare compliance is required for them due to the chronic and relapsing nature of their diseases. However, little is known about expectations among Chinese patients with mental disorders.

Objective: To examine expectations for healthcare among patients with mental disorders and to compare them with those of patients with chronic physical diseases.

Patients and methods: A cross-sectional survey was conducted among two inpatient groups, consecutively recruited from the Mental Health Department (MHD) and Endocrinology Department (ED) in one tertiary general hospital in Changsha, China. Patient expectations were measured by eight translated and modified vignettes of health system responsiveness. Group differences were compared using Chi-square tests for sociodemographic and clinical characteristics and Z-test for expectation rating. Logistic regression was performed to test whether group differences of expectations remained statistically significant after controlling for socio-demographic and clinical variables.

Results: Most patients from MHD rated scenarios in vignettes on communication, choice of provider, autonomy, and social support as "meeting expectations", and rated scenarios in vignettes on prompt attention, dignity, confidentiality, and quality of basic amenities as "below expectations". In comparison, patients from MHD had similar expectations with their counterparts from ED, for prompt attention, dignity, confidentiality, communication, choice of provider, and social support; however, patients from MHD had significantly lower expectations in quality of basic amenities and higher expectations in autonomy, after adjusting for socio-demographic and clinical factors.

Conclusion: Like their counterparts with physical diseases, patients with mental disorders also expect prompt attention, dignity, confidentiality, communication, choice of provider, and social support in their interaction with the healthcare system. Moreover, extra attention to autonomy is needed for patients with mental disorders to meet their expectations and improve patient satisfaction.

Keywords: patient expectations, responsiveness, mental health, China

\section{Introduction}

As patient-centered approaches have gained an important place in healthcare delivery, ${ }^{1,2}$ there is also increasing interest in patient expectations, which refer to the anticipation or the belief about what should be encountered in the healthcare system. ${ }^{3}$ Understanding and meeting patient expectations can improve satisfaction, 
through reducing the gap between patients' experience and expectations. ${ }^{4,5}$ When patients get their healthcare expectations responded, they tend to exercise greater adherence, which can positively affect their health outcomes and reduce costs of healthcare delivery. ${ }^{6,7}$

The chronic and relapsing nature of mental disorders needs patients to have great adherence to treatment lasting for years. ${ }^{8}$ However, the characteristics of mental disorders and some coercive treatment not only increase patients' stigma but also put patients on greater risk of right violation in healthcare, which may reduce patients' motivation to seek healthcare. ${ }^{9,10}$ Moreover, previous studies on patients with mental disorders found that when expectations are incongruent with the services received, poorer clinical outcomes are likely to be present. ${ }^{11,12}$ Therefore, understanding and responding to healthcare expectations is of particular significance for patients with mental disorders.

There are a large amount of qualitative and quantitative studies on patient expectations for mental health services. Their results show that patients not only desire clinically effective interventions and improvement on their mental conditions, but also want involvement in decision making and a good relationship with providers. ${ }^{11-15}$ However, mental health services are not the only clinical setting that patients with mental disorders will experience, considering the global promotion integrated mental health services by the World Health Organization (WHO) ${ }^{16}$ and the prevalent comorbidity of mental and physical diseases. ${ }^{17,18}$ Thus, asking patients with mental disorders for their expectations for health services, instead of merely for mental health services, is a new but important question. In addition, the aforementioned previous studies are mainly conducted in the United States, Canada, and Europe. ${ }^{1-15}$ There is no knowledge on expectations of patients with mental disorders in China, not even on patient expectations for mental health services in China, where the weighted lifetime prevalence of any mental disorder (excluding dementia) among the adult population is $16.6 \%{ }^{19}$

Previous studies on patient expectations are mainly conducted in homogeneous populations with specific diseases; ${ }^{20-22}$ however, we believe that it is important to have healthcare expectations of patients with mental disorders compared with those of patients with physical diseases, at least for non-medical aspects of patient expectations. The comparison can give healthcare providers and planners insights and special awareness of potentially different needs from the patients with mental disorders.

Therefore, this study has twofold objectives: 1) to evaluate healthcare expectations of Chinese patients with mental disorders; and 2) to compare health expectations between patients with mental disorders and ones with chronic physical diseases.

\section{Methods \\ Study Design And Samples}

The present study was part of an evaluation program on responsiveness of the mental health system in China, which aimed to evaluate patient experience and improve the healthcare quality of China's mental health system. For the present study, a cross-sectional survey was designed and conducted from June 1 to July 31, 2018 among two inpatient groups consecutively recruited from six wards in the MHD and one ward in the ED in one of the largest general tertiary hospitals in Changsha, the capital city of Hunan Province, China. We chose the ED in comparison with the MHD for two reasons: 1) ED covered a large range of chronic physical diseases commonly found in adult population, like diabetes, metabolic syndrome, and thyroid diseases. 2) ED and MHD were the two best clinical departments in the selected hospital, judging both in both clinical and nonmedical aspects.

Patients fulfilling the following criteria were approached for survey: 1) were older than 18 years of age; 2) were physically and mentally capable of following the interview according to their clinical records; and 3) were discharged at our investigation period. We excluded patients who were admitted for substance abuse.

We conducted face-to-face interviews at patient discharge or on the day before discharge. Before the interview, all participants were informed that the completion of the questionnaire was voluntary and that they could withdraw from the study at any time. Written informed consents were signed by all participants and one family member of each patient from the MHD. This study was approved by the Institutional Review Board of the Xiangya School of Public Health, Central South University (XYGW-2018-01).

Data, including socio-demographics, clinical information, and patient expectations, were collected using faceto-face interviews at patient discharge or on the day before discharge. All interviewers were postgraduate students 
with a background in public health. Before the formal investigation, all interviewers received 1-week of uniform training to conduct the interviews, which included questionnaire specifications, interview skills, role-play practice of interviewing, and briefing on mental disorders they might come across in the survey.

\section{Measures}

\section{Socio-Demographic Characteristics}

Socio-demographic characteristics were collected through a self-designed questionnaire, including age, gender (male, female), place of residence (urban, rural), marital status (single, married/cohabiting, divorced/separated/widowed), education (primary school or below, junior high school, high school, college or above), employment (employed, unemployed, retired, student, caring for family) and health insurance coverage (yes/no).

\section{Clinical Information}

Clinical information included diagnosis, time from diagnosis, and duration of treatment. Time from diagnosis and duration of treatment were categorized into: i) 5 years or less; and ii) more than 5 years. We also collected information on whether participants received inpatient treatment in multiple hospitals in the past 3 years (yes/no).

\section{Patient Expectations}

Measurement of patient expectations was based on the concept of responsiveness, which was proposed by the WHO as one of the three intrinsic goals of the health system. $^{23}$ The core of responsiveness is responding to the population's universally legitimate expectations regarding non-medical aspects of health services. According to responsiveness, patients' expectations can be assessed in eight domains: prompt attention, dignity, confidentiality, communication, quality of basic amenities, choice of provider, autonomy, and social support. ${ }^{24}$

In this study, patient expectations for health services were measured by eight vignettes, which were selected from vignettes of health system responsiveness used in the World Health Survey and the WHO Study on Global Ageing and Adult Health (SAGE) (2007-2008). ${ }^{24,25}$ The original purpose of WHO's introducing responsiveness vignette was to control reporting heterogeneity and permit better comparison of self-reported service quality and satisfaction across populations. ${ }^{24,26}$ Now the method of vignette has been used as a measurement to patient expectations in several recent studies. ${ }^{27,28}$

Each selected vignette provided one scenario of people's experience with health services and tested one domain of health system responsiveness. WZ, a researcher with a Ph.D. degree in Public Health and 7-years of research experience of Chinese mental health policy and services, translated the eight vignettes into simplified Chinese. Necessary modifications, like giving common Chinese names and titles to persons presented in the vignette, were made to help the participants feel connected to the presented scenarios. The Chinese version of the vignettes was reviewed and finalized by SYX, who was a senior psychiatrist and a professor of public health. The full texts of the eight modified vignettes are provided in Table 1.

Participants were asked to think about the given scenarios as their own experience and then to rate each scenario based on a five-point Likert scale: very poor (1), poor (2), moderate (3), good (4), very good (5). The score of each vignette reflected expectation for one responsiveness domain, and higher score reflected lower expectation. When "very poor" (1) or "poor" (2) were rated, the scenarios presented in vignettes were considered as being below respondents' expectations (below expectation); when "moderate" (3), "good" (4) or "very good" (5) was rated, the scenarios were considered as meeting respondents' expectations (meeting expectation).

\section{Data Analysis}

Descriptive statistics were used to summarize participants' socio-demographic and clinical characteristics, and expectation outcomes. Group differences of sociodemographic and clinical characteristics between patients from MHD and ED were tested using Chi-square tests and the expectation rating of the two inpatient groups were compared using Z-test. For responsiveness domains with statistical significance between patients from MHD and ED, multivariable logistic regressions were performed separately for each domain, to test whether group differences remain statistically significant after controlling for socio-demographic and clinical variables. The detailed procedures were as follows: we first performed univariate logistic regressions separately for each domain. Variables with a $P$-value $\leq 0.1$ in univariate analysis were then selected in the multivariate analysis. All 
Table I Vignettes Used To Measure Patient Expectations

\begin{tabular}{|c|c|}
\hline $\begin{array}{l}\text { Domain Of } \\
\text { Responsiveness }\end{array}$ & Vignettes \\
\hline Prompt attention & $\begin{array}{l}\text { [Xiao Wang] broke his leg. It took an hour to be driven to the nearest hospital. He was in pain but had to wait an hour } \\
\text { for the surgeon and was arranged for operation on the next day. }\end{array}$ \\
\hline Dignity & $\begin{array}{l}\text { [Miss Zhang] went to a crowded clinic. No-one greeted her. She waited for } 30 \text { minutes when a nurse called to her for } \\
\text { an examination behind a screen that separated the waiting area from the examination area. }\end{array}$ \\
\hline Confidentiality & $\begin{array}{l}\text { [Mr. Jiang] had his consultation in a private room. During the consultation, a nurse occasionally walked in and listened } \\
\text { to the conversation. Sometimes she forgot to close the door so people in the waiting room could overhear parts of } \\
\text { their conversation. }\end{array}$ \\
\hline Communication & $\begin{array}{l}\text { [Mr. Li] has been told that he has epilepsy and that he needs to take medication. The doctor has very briefly explained } \\
\text { what the condition is. He is very busy and there is a queue of patients waiting to see him. [Mr. Li] would like to know } \\
\text { more about what he has, but feels that there is no time to ask questions, so Mr. Li leaves the office. }\end{array}$ \\
\hline $\begin{array}{l}\text { Quality of basic } \\
\text { amenities }\end{array}$ & $\begin{array}{l}\text { [Uncle Ma] shared a hospital room with four other persons. There was a toilet for his ward located along the outside } \\
\text { corridor. The room was cleaned once a week, was occasionally dusty, and had only one or two chairs for visitors. }\end{array}$ \\
\hline Choice of provider & $\begin{array}{l}\text { When the clinic is not busy, [Aunt Liao] can choose which doctor she sees. But most often it is busy and then she gets } \\
\text { sent to whoever is free. }\end{array}$ \\
\hline Autonomy & $\begin{array}{l}\text { [Uncle Lei] had a broken arm. The doctor explained different ways of fixing it and then ordered some blood tests. } \\
\text { [Uncle Lei] did not know why he needed blood tests and was worried until the doctor explained what they were for }\end{array}$ \\
\hline Social support & $\begin{array}{l}\text { [Ms. Dong] gave birth in hospital. Her husband was permitted to visit her every morning and evening. [Ms. Dong] was } \\
\text { able to contact her family and friends once a day. }\end{array}$ \\
\hline
\end{tabular}

analyses were performed in SPSS 18.0 and a significant level of 0.05 was applied.

\section{Results}

\section{Participant Characteristics}

In the survey, we approached 298 patients from MHD and 211 patients from ED. In MHD, 64 patients refused to participate; in ED, 30 patients refused to participate and 21 withdrew during the survey. The responding rates were $78.52 \%$ in the $\mathrm{MDH}$ and $75.83 \%$ in the ED. After excluding eight incomplete ones, we had 228 valid questionnaires from the MHD and 158 from the ED for analysis. For patients from MHD, 44.3\% (101) were diagnosed with depression and/or anxiety, 19.74\% (45) were psychotic disorders, and $16.67 \%$ (38) were bipolar disorder. For patients from ED, 50\% (79) were diagnosed with diabetes and $10.2 \%$ (16) were metabolic syndrome or thyroid diseases. Most of the participants from both departments lived in urban areas and were covered by health insurance. Both groups had an almost equal distribution in gender (Table 2). However, compared with their counterparts from the ED, patients from MHDs were younger and more likely to be single, have a higher education level, have shorter time from diagnosis and shorter duration of treatment, and were less likely to be retired, and receive inpatient treatment in multiple hospitals, all with $P<0.05$ (Table 2).

\section{Patient Expectations Based On Vignettes}

Table 3 demonstrated participants' expectation outcomes based on the vignettes. Most participants from both departments found that vignettes on choice of providers, autonomy, and social support presented scenarios were in accordance with or exceeding their expectations for health services (expectation score $\geq 3$ ); almost half of them agreed that healthcare experience provided in vignettes on communication met their expectations (expectation score $\geq 3$ ); most of them rated vignettes on prompt attention, dignity, confidentiality, and quality of basic amenities below their expectations (expectation score $<3$ ). In comparison, more patients from the MHD (25\%) rated the vignette on basic amenities as "meeting expectations" than ones from the ED (11.4\%), with $P<0.05$. A significantly slower proportion of patients from the MHD (79.4\%) considered the vignette on autonomy meet their expectations than their counterparts from the ED (88.5\%), also with $P<0.05$. The results indicated that patients from the MHD had lower 
Table 2 Sample Characteristics

\begin{tabular}{|c|c|c|c|}
\hline & $\begin{array}{l}\text { Patients } \\
\text { From MHD } \\
(n=228)\end{array}$ & $\begin{array}{l}\text { Patients } \\
\text { From ED } \\
n=(58)\end{array}$ & $P$-value \\
\hline \multicolumn{4}{|c|}{ Socio-demographic characteristics } \\
\hline $\begin{array}{l}\text { Age } \\
\qquad \begin{array}{r}18-40 \\
4 I-60 \\
6 I-85\end{array}\end{array}$ & $\begin{array}{l}136(59.6) \\
80(35.1) \\
12(5.3)\end{array}$ & $\begin{array}{l}28(17.7) \\
70(44.3) \\
60(38.0)\end{array}$ & $<0.001$ \\
\hline $\begin{array}{l}\text { Gender } \\
\text { Male } \\
\text { Female }\end{array}$ & $\begin{array}{l}105(46.1) \\
123(53.9)\end{array}$ & $\begin{array}{l}80(50.6) \\
78(49.4)\end{array}$ & 0.376 \\
\hline $\begin{array}{l}\text { Place of residence* } \\
\text { Urban } \\
\text { Rural }\end{array}$ & $\begin{array}{l}|3|(57.5) \\
8 \mid(35.5)\end{array}$ & $\begin{array}{l}97(61.4) \\
49(31.0)\end{array}$ & 0.369 \\
\hline $\begin{array}{l}\text { Marital status* } \\
\text { Single } \\
\text { Married/Cohabiting } \\
\text { Separated/Divorced/ } \\
\text { Widowed }\end{array}$ & $\begin{array}{l}87(38.2) \\
126(55.3) \\
13(5.7)\end{array}$ & $\begin{array}{l}17(10.8) \\
128(8 \mid .0) \\
13(8.2)\end{array}$ & $<0.001$ \\
\hline 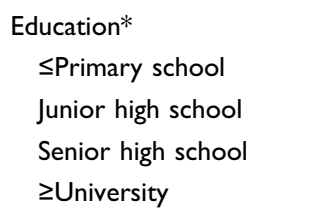 & $\begin{array}{l}19(8.3) \\
60(26.3) \\
56(24.6) \\
92(40.4)\end{array}$ & $\begin{array}{l}48(30.4) \\
38(24.1) \\
38(24.1) \\
34(21.5)\end{array}$ & $<0.001$ \\
\hline $\begin{array}{l}\text { Occupation* } \\
\text { Employed } \\
\text { Retired } \\
\text { Student } \\
\text { Caring for family } \\
\text { Unemployed }\end{array}$ & $\begin{array}{l}86(37.7) \\
18(7.9) \\
31(13.6) \\
16(7.0) \\
76(33.3)\end{array}$ & $\begin{array}{l}51(32.3) \\
45(28.5) \\
4(2.5) \\
10(6.3) \\
45(28.5)\end{array}$ & $<0.001$ \\
\hline $\begin{array}{l}\text { Health insurance coverage } \\
\text { Yes } \\
\text { No }\end{array}$ & $\begin{array}{l}214(93.9) \\
14(6.1)\end{array}$ & $\begin{array}{l}\text { I57 (99.4) } \\
\text { I }(0.6)\end{array}$ & 0.006 \\
\hline Clinical characteristics & & & \\
\hline $\begin{array}{l}\text { Time from diagnosis* } \\
\leq 5 \text { years } \\
>5 \text { years }\end{array}$ & $\begin{array}{l}169(73.7) \\
52(22.8)\end{array}$ & $\begin{array}{l}82(51.9) \\
68(43.0)\end{array}$ & $<0.001$ \\
\hline $\begin{array}{l}\text { Duration of treatment* } \\
\quad \leq 5 \text { years } \\
>5 \text { years }\end{array}$ & $\begin{array}{l}189(82.9) \\
31(13.6)\end{array}$ & $\begin{array}{l}86(54.4) \\
62(39.2)\end{array}$ & $<0.001$ \\
\hline $\begin{array}{l}\text { Admission in multi- } \\
\text { hospitals last } 3 \text { years } \\
\text { Yes } \\
\text { No }\end{array}$ & $\begin{array}{l}7 \mid(31.1) \\
157(68.9)\end{array}$ & $\begin{array}{l}78(49.4) \\
80(50.6)\end{array}$ & $<0.001$ \\
\hline
\end{tabular}

Notes: Data are shown as $\mathrm{n}(\%)$. All P-values in the table were from Chi-squared tests. *There are missing data. expectations in basic amenities and higher expectations in autonomy than patients from the ED.

\section{Predictors Of Expectation Difference}

Both univariate and multivariate logistic regressions were conducted for domains of quality of basic amenities and autonomy. Based on the results of univariate analysis $(P \leq 0.10)$, inpatient department, age, health insurance coverage, time from diagnosis, and duration of treatment were selected as potential explanatory variables in the multivariate logistic model for quality of basic amenities (Table 4). In the final multivariate logistic model, the OR (odds ratio) of the inpatient department was 2.333 $(P=0.007)$, which indicated that patients from the MHD had lower expectations in the quality of basic amenities after adjustment for demographic and socio-demographic variables; the OR of time from diagnosis was 0.465 $(P=0.028)$, which indicated that a longer time from diagnosis ( $>5$ years) was a risk factor of high expectations in the quality of basic amenities (Table 5).

Based on the results of univariate analysis $(P \leq 0.10)$, inpatient department, age, and education level were selected in the multivariate logistic model for autonomy (Table 4). In the final multivariate logistic model, the OR of the inpatient department was $0.521(P=0.049)$, indicating that patients from the MHD had higher expectations in autonomy, after adjusting for demographic and sociodemographic variables; the OR of age between 41-60 years was $0.532(P=0.038)$ and the OR of age above 60 years was 1.653 , but without statistical significance, which indicated that patients aged between 41-60 years had higher expectations in autonomy.

\section{Discussion}

To our best knowledge, this is the first study to examine expectations for healthcare among patients with mental disorders and to compare them with those of patients with chronic physical diseases. According to the results, patients from both departments shared similar healthcare expectations for prompt attention, dignity, confidentiality, communication, choice of provider, social support: scenarios in vignettes on communication, choice of provider, autonomy, and social support were rated as "meeting expectations", and scenarios in vignettes on prompt attention, dignity, confidentiality, and quality of basic amenities were rated as "below expectations". Differences were 
Table 3 Patient Expectations Based On Vignettes

\begin{tabular}{|l|l|l|l|l|l|}
\hline Domains & Outcomes & Patients From MHD & Patients From ED & Z test & P-value \\
\hline Prompt attention & $\begin{array}{l}\text { Meeting expectation } \\
\text { Below expectation }\end{array}$ & $\begin{array}{l}70(30.8) \\
157(57.1)\end{array}$ & $\begin{array}{l}40(25.3) \\
\text { II8 (42.9) }\end{array}$ & 1.19 I & 0.234 \\
\hline Dignity & $\begin{array}{l}\text { Meeting expectation } \\
\text { Below expectation }\end{array}$ & $\begin{array}{l}112(49.1) \\
116(50.9)\end{array}$ & $\begin{array}{l}67(42.4) \\
91(57.6)\end{array}$ & 1.303 \\
\hline Confidentiality & $\begin{array}{l}\text { Meeting expectation } \\
\text { Below expectation }\end{array}$ & $\begin{array}{l}82(36.0) \\
146(64.0)\end{array}$ & $\begin{array}{l}67(42.4) \\
91(57.6)\end{array}$ & 1.270 \\
\hline Communication & $\begin{array}{l}\text { Meeting expectation } \\
\text { Below expectation }\end{array}$ & $\begin{array}{l}116(50.9) \\
112(49.1)\end{array}$ & $\begin{array}{l}76(48.1) \\
82(51.9)\end{array}$ & 0.205 \\
\hline Quality of basic amenities & $\begin{array}{l}\text { Meeting expectation } \\
\text { Below expectation }\end{array}$ & $\begin{array}{l}57(25.0) \\
171(75.0)\end{array}$ & $\begin{array}{l}18(11.4) \\
140(88.6)\end{array}$ & 3.535 \\
\hline Choice of provider & $\begin{array}{l}\text { Meeting expectation } \\
\text { Below expectation }\end{array}$ & $\begin{array}{l}130(57.0) \\
98(43.0)\end{array}$ & $\begin{array}{l}97(61.4) \\
61(38.6)\end{array}$ & 0.593 \\
\hline Autonomy & $\begin{array}{l}\text { Meeting expectation } \\
\text { Below expectation }\end{array}$ & $\begin{array}{l}181(79.4) \\
47(20.6)\end{array}$ & $\begin{array}{l}139(88.5) \\
18(11.5)\end{array}$ & 0.857 \\
\hline Social support & $\begin{array}{l}\text { Meeting expectation } \\
\text { Below expectation }\end{array}$ & $\begin{array}{l}185(81.5) \\
42(18.5)\end{array}$ & $\begin{array}{l}127(80.9) \\
30(19.1)\end{array}$ & 2.470 \\
\hline
\end{tabular}

Notes: Data are shown as $\mathrm{n}(\%)$. All P-values in the column were from $Z$ test. Meeting expectation: expectation scores=3, 4, or 5 . Below expectation: expectation scores=I or 2 .

detected in domains of quality of basic amenities and autonomy: patients from the MHD had lower expectations in basic amenities and a higher expectation in autonomy.

Unlike many previous expectation studies, we measured patient expectations by vignettes, rather than importance rating on healthcare components ${ }^{29,30}$ or patient satisfaction/dissatisfaction. ${ }^{12,31}$ Through scenarios presented in vignettes, our results provide descriptions on what good or bad services look like, which will give healthcare providers more concrete suggestions on what they should do or not do in their interaction with patients.

Prompt attention, as one of the four domains below most patients' expectations, evaluates whether care is provided readily or as soon as possible with the measurement of waiting time. ${ }^{24}$ One-hour waiting presented in the vignette is not very long, compared with the average waiting time of 57-150 minutes in China's outpatients of tertiary hospitals $^{32,33}$ and the recommended standard waiting time of emergency departments (120 minutes) in Canada. ${ }^{34}$ As around $70 \%$ or more patients of both departments rated the waiting time as "below expectation", it demonstrates a really demanding requirement for short waiting time for health services among Chinese patients. The extraordinarily high demand for quick access to health services could also explain why patients were least satisfied with long waiting times for consultation in a previous national healthcare survey in China. ${ }^{35}$

Dignity, as another domain below most patients' expectations, refers to receiving care in a respectful, caring, and non-discriminatory setting. ${ }^{24}$ In the vignette of this domain, no greeting at all from healthcare presents a poor-quality healthcare, judging from clinician greeting manners in international literature. ${ }^{36,37}$ Despite the poor quality of healthcare presented in the dignity vignette, the proportion of patients rated "below expectation" on dignity $(50-58 \%)$ is lower that that on prompt attention (70\%), which implies a relatively lower requirement for dignity than prompt attention among Chinese patients.

The vignette of confidentiality, presenting a scenario of overhearing patient-doctor conversations, was also rated as "below expectation" by $64 \%$ of patients from the MHD and $58 \%$ of patients from the ED. Surveys in the United States and Australia reported that around $40 \%$ of patients once overheard other patients' conversations with clinicians. ${ }^{38,39}$ Though there is no reporting on overhearing in China, we estimate it is also common, considering the over-crowdedness in Chinese hospitals. ${ }^{40}$ When privacy cannot be guaranteed as expected, patients may be reluctant to share personal information or even not seek healthcare. ${ }^{38,41}$ Therefore, efforts are needed to protect healthcare confidentiality and reduce overhearing. 
Table 4 Univariate Logistic Regression Model For Patients' Expectation Based On Vignettes In Quality Of Basic Amenities And Autonomy

\begin{tabular}{|c|c|c|c|c|}
\hline \multirow[t]{2}{*}{ Variables } & \multicolumn{2}{|l|}{ Basic Amenities } & \multicolumn{2}{|l|}{ Autonomy } \\
\hline & OR (95\% Cl) & $P$-value & OR (95\% CI) & $P$-value \\
\hline \multicolumn{5}{|l|}{ Inpatient department } \\
\hline ED & Ref & & Ref & \\
\hline MHD & $2.593(1.459-4.608)$ & 0.001 & $0.499(0.277-0.897)$ & 0.020 \\
\hline \multicolumn{5}{|l|}{ Age } \\
\hline $18-40$ & Ref & & Ref & \\
\hline $4 I-60$ & $0.455(0.258-0.802)$ & 0.006 & $0.637(0.361-1.124)$ & 0.120 \\
\hline $6 I-85$ & $0.331(0.147-0.744)$ & 0.007 & $2.525(0.928-6.867)$ & 0.070 \\
\hline \multicolumn{5}{|l|}{ Gender } \\
\hline Male & Ref & & Ref & \\
\hline Female & $0.996(0.602-1.650)$ & 0.989 & $1.058(0.621-1.804)$ & 0.835 \\
\hline \multicolumn{5}{|l|}{ Place of residence } \\
\hline Urban & Ref & & Ref & \\
\hline Rural & $1.272(0.747-2.164)$ & 0.376 & $0.987(0.555-1.756)$ & 0.965 \\
\hline \multicolumn{5}{|l|}{ Marital status } \\
\hline Single & Ref & & Ref & \\
\hline Married/Cohabiting & $0.492(0.284-0.855)$ & 0.012 & $0.739(0.393-1.390)$ & 0.348 \\
\hline Separated/Divorced/Widowed & $1.000(0.380-2.635)$ & 1.000 & $1.292(0.345-4.845)$ & 0.704 \\
\hline \multicolumn{5}{|l|}{ Education level } \\
\hline SPrimary school & Ref & & Ref & \\
\hline Junior high school & $1.748(0.77 I-3.962)$ & 0.181 & $0.836(0.357-1.959)$ & 0.680 \\
\hline Senior high school & $1.082(0.454-2.582)$ & 0.859 & $\mathrm{I} .308(0.52 \mathrm{I}-3.284)$ & 0.568 \\
\hline$\geq$ University & $1.555(0.702-3.444)$ & 0.277 & $0.643(0.290-1.425)$ & 0.277 \\
\hline \multicolumn{5}{|l|}{ Occupation } \\
\hline Employed & Ref & & Ref & \\
\hline Retired & $0.845(0.379-1.887)$ & 0.682 & $1.58 I(0.67 I-3.723)$ & 0.295 \\
\hline Student & $1.551(0.648-3.714)$ & 0.325 & $1.815(0.589-5.594)$ & 0.299 \\
\hline Caring for family & $0.815(0.258-2.573)$ & 0.727 & $1.796(0.50 \mathrm{I}-6.437)$ & 0.369 \\
\hline Unemployed & $1.287(0.700-2.366)$ & 0.417 & $0.947(0.510-1.756)$ & 0.862 \\
\hline \multicolumn{5}{|l|}{ Health insurance coverage } \\
\hline Yes & Ref & & Ref & \\
\hline No & $2.908(1.002-8.44 I)$ & 0.050 & $0.545(0.168-1.767)$ & 0.312 \\
\hline \multicolumn{5}{|l|}{ Time from diagnosis } \\
\hline$\leq 5$ years & Ref & & Ref & \\
\hline$>5$ years & $0.370(0.190-0.719)$ & 0.003 & $1.210(0.666-2.200)$ & 0.531 \\
\hline \multicolumn{5}{|l|}{ Duration of treatment } \\
\hline$\leq 5$ years & Ref & & Ref & \\
\hline$>5$ years & $0.451 \quad(0.227-0.899)$ & 0.024 & $1.583(0.784-3.195)$ & 0.200 \\
\hline \multicolumn{5}{|l|}{ Admission in multi-hospitals last 3 years } \\
\hline Yes & Ref & & Ref & \\
\hline No & $1.540(0.897-2.644)$ & 0.118 & $0.667(0.376-1.181)$ & 0.165 \\
\hline
\end{tabular}

Notes: Outcome I=meeting expectation, $0=$ below expectation.

Though most patients from both departments rated the significantly lower expectation for this domain was found vignette of basic amenities as "below expectation", a among patients from the MHD. As expectations are 
Table 5 Multivariate Logistic Regression Model For Patients' Expectation Based On Vignettes In Quality Of Basic Amenities And Autonomy

\begin{tabular}{|c|c|c|c|c|}
\hline \multirow[t]{2}{*}{ Explanatory Variables } & \multicolumn{2}{|c|}{ Quality Of Basic Amenities } & \multicolumn{2}{|l|}{ Autonomy } \\
\hline & Odds Ratio $(95 \% \mathrm{CI})$ & $P$-value & Odds Ratio $(95 \% \mathrm{CI})$ & $P$-value \\
\hline \multicolumn{5}{|l|}{ Inpatient department } \\
\hline ED & Ref & & Ref & \\
\hline MHD & $2.333(1.259-4.323)$ & 0.007 & $0.521(0.272-0.997)$ & 0.049 \\
\hline \multicolumn{5}{|l|}{ Age } \\
\hline $18-40$ & & & Ref & \\
\hline $4 I-60$ & & & $0.532(0.293-0.964)$ & 0.038 \\
\hline $61-85$ & & & $1.653(0.559-4.885)$ & 0.364 \\
\hline \multicolumn{5}{|l|}{ Time from diagnosis } \\
\hline$\leq 5$ years & Ref & & & \\
\hline$>5$ years & $0.465(0.235-0.921)$ & 0.028 & & \\
\hline
\end{tabular}

Notes: Outcome I=meeting expectation, $0=$ below expectation. Method of logistic regression: backward.

formed from patients' previous experience with health services, ${ }^{42}$ the group difference of expectations for basic amenities can be a reflection of poorer environment of mental health wards, which patients with mental disorders have to face throughout their healthcare experience. Evaluation studies on responsiveness of mental health services in Germany and Iran also reported the poor quality of basic amenities. ${ }^{9,10}$ Poor mental healthcare facilities can be attributed to the universal and constant neglect of mental disorders and insufficient input of resources, especially in developing countries. ${ }^{43}$ In China, the median number of psychiatric beds in mental hospitals is 0.215 per 100,000 population, ${ }^{44}$ which is far below the median number of 11.3 mental hospital beds per 100,000 population globally. ${ }^{45}$ Given that the median length of inpatient stay in Chinese psychiatric hospitals is 45 days ${ }^{46}$ psychiatric wards are always crowded with patients. As mental health beds are unequally distributed in China, ${ }^{46}$ remote regions can have even more crowded mental health wards. Because healthcare environment can positively affect patients' well-being, ${ }^{47}$ efforts are very much needed to improve the quality of basic amenities in mental healthcare, despite the lower expectation for basic amenities among patients with mental disorders.

Most patients from both departments agreed that vignettes of autonomy met their expectations, but the results of group comparison indicated that patients from the MHD had significantly higher expectation for this domain. This is consistent with previous studies on patient expectations for mental health services, which found that the desire to make decisions for patients themselves was the single most common request from patients with mental disorders. ${ }^{12}$ Unlike physical diseases, symptom examination, rather than biochemical tests, play a more important role when psychiatrists diagnose mental disorders and judge change of patients' conditions. ${ }^{48}$ Thus, discussion on patients' medical conditions between patients and clinicians is more routine in the MHD than in other medical departments like the ED. That can be a possible reason why patients from the MHD feel more involved in their healthcare decision-making and hold higher expectations for autonomy.

One study comparing healthcare expectations between patients with and without HIV (human immunodeficiency virus infection) showed that disease-related stigma could influence the level of patient expectation and that statistical differences were found in all eight domains of responsiveness. ${ }^{27}$ In China, mental disorders are also associated with stigma, and patients with mental disorders are likely to have negative experiences and discrimination when receiving health services. ${ }^{49,50}$ However, statistical differences of expectations between patients from the MHD and ED were only detected in two domains in our study. Potential explanations for that could be that almost half of the patients from the MHD in this study were diagnosed with depression and/or anxiety. Stigma and discrimination for the above mental disorders are much less severe than psychotic illnesses like schizophrenia. ${ }^{51}$ During our survey, some patients with anxiety and/or depression told us that their mental disorders are just as common as hypertension or diabetes or even the common cold and that they were not ashamed of their diseases. 
However, stigma of HIV is still serious in China ${ }^{52}$ and is identified as an explanation for HIV patients' much lower expectations for health services. $^{27}$

\section{Limitations}

Due to the consideration of feasibility under a limited project time and funding, we have used a hospital sample in this study, which unavoidably drops off patients who do not seek health services. Furthermore, our samples were recruited from one of the best tertiary hospitals in the middle south part of China. Therefore, patients, particularly ones from the MHD, have a higher socio-economic status than community-based samples used in other mental health research. ${ }^{53}$ Because of the selection bias, there is a limitation on the generalization of this research's conclusion, and further study based on a community sample is needed.

\section{Conclusion}

Based on the results of comparing patient expectations between patients from the MHD and ED, it is suggested that patients with mental disorders should receive unbiased health services like their counterparts with physical diseases, in terms of prompt attention, dignity, confidentiality, communication, choice of provider, and social support. Furthermore, clinicians should consider more autonomy for patients with mental disorders throughout their clinical practice. More efforts should also be put on improving the quality of basic amenities in mental healthcare.

Like their counterparts with physical diseases, patients with mental disorders also expect prompt attention, dignity, confidentiality, communication, choice of provider, and social support in their interaction with the healthcare system. As patients with mental disorders tend to have higher expectations to autonomy, more efforts to involve patients with mental disorders in the decision-making of their own health and treatment is needed, to meet their expectations and improve patient satisfaction. In addition, more attention should also be paid to the quality of basic amenities in mental healthcare.

\section{Acknowledgments}

This research is supported by the National Social Science Foundation of China (17CGL050) to Wei Zhou. We also would like to thank the Mental Health Department and the Department of Metabolism and Endocrinology in Second Xiangya Hospital, Central South University, for their assistance in data collection.

\section{Disclosure}

The authors report no conflicts of interest in this work.

\section{References}

1. Laine C, Davidoff F. Patient-centered medicine. A Professional Evolution. Jama. 1996;275(2):152-156.

2. Lionis C, Papadakis S, Tatsi C, et al. Informing primary care reform in Greece: patient expectations and experiences (the QUALICOPC study). Bmc Health Serv Res. 2017;17:13.

3. Kravitz RL. Patients' expectations for medical care: an expanded formulation based on review of the literature. Med Care Res Rev. 1996;53(1):3-27.

4. Ross CK, Frommelt G, Hazelwood L, Chang RW. The role of expectations in patient satisfaction with medical care. $J$ Health Care Mark. 1987;7(4):16-26.

5. Thompson AG, Sunol R. Expectations as determinants of patient satisfaction: concepts, theory and evidence. Int J Qual Health Care. 1995;7(2):127-141.

6. Alrashdi I. Evaluation of quality of healthcare: to what extent can we rely on patient expectations and preferences. Oman Med J. 2012;27 (6):448-449.

7. Forouzan AS, Ghazinour M, Dejman M, Rafeiey H, Eftekhari MB, Sebastian MS. Service users and providers expectations of mental health care in Iran: a qualitative study. Iran J Public Health. 2013;42 (10):1106-1116.

8. Forouzan AS, Ghazinour M, Dejman M, Rafeiey H, Sebastian MS. Testing the WHO responsiveness concept in the Iranian mental healthcare system: a qualitative study of service users. Bmc Health Serv Res. 2011;11:10.

9. Bramesfeld A, Wedegartner F, Elgeti H, Bisson S. How does mental health care perform in respect to service users' expectations? Evaluating inpatient and outpatient care in Germany with the WHO responsiveness concept. Bmc Health Serv Res. 2007;7:12.

10. Forouzan S, Padyab M, Rafiey H, Ghazinour M, Dejman M, San Sebastian M. Measuring the mental health-care system responsiveness: results of an outpatient survey in Tehran. Front Public Health. 2016;3:8.

11. Noble LM, Douglas BC, Newman SP. What do patients expect of psychiatric services? A systematic and critical review of empirical studies. Soc Sci Med. 2001;52(7):985-998.

12. Noble L, Douglas B. What users and relatives want from mental health services. Curr Opin Psychiatry. 2004;17(4):289-296.

13. Bee P, Playle J, Lovell K, et al. Service user views and expectations of UK-registered mental health nurses: a systematic review of empirical research. Int J Nurs Stud. 2008;45(3):442-457.

14. Noble LM, Douglas BC, Newman SP. What do patients want and do we want to know? A review of patients' requests of psychiatric services. Acta Psychiatr Scand. 1999;100(5):321-327. doi:10.1111/ j.1600-0447.1999.tb10874.x

15. Shiina A, Ojio Y, Sato A, et al. The recognition and expectations of ex-inpatients of mental health services: a web-based questionnaire survey in Japan. PLoS One. 2018;13(10):e0197639.

16. World Health Organization/World Organization of Family Doctors. Integrating Mental Health into Primary Care: A Global Perspective. Geneva: World Health Organization; 2008.

17. Leucht S, Burkard T, Henderson J, et al. Physical illness and schizophrenia: a review of the literature. Acta Psychiatr Scand. 2007;116 (5):317-333.

18. Scott KM, Lim C, Al-Hamzawi A, et al. Association of mental disorders with subsequent chronic physical conditions: World Mental Health Surveys from 17 countries. JAMA Psychiatry. 2016;73(2):150-158.

19. Huang Y, Wang Y, Wang H, et al. Prevalence of mental disorders in China: a cross-sectional epidemiological study. Lancet Psychiatry. 2019;6(3):211-224. 
20. Staniszewska S, Ahmed L. The concepts of expectations and satisfaction: do they capture the way patient evaluate their care? J Adv Nurs. 1999;29:364-372. doi:10.1046/j.1365-2648.1999.00897.x

21. Conner-Spady BL, Sanmartin C, Johnston GH, et al. The importance of patient expectations as a determinant of satisfaction with waiting times for hip and knee replacement surgery. Health Policy. 2011;101 (3):245-252.

22. Delgado A, Andrés López-Fernández LA, Luna JD, et al. Patient expectations are not always the same. J Epidemiol Community Health. 2008;62:427-434.

23. World Health WHO. Report 2000: Health Systems:Improving Perdormance. Geneva: World Health Organization; 2000.

24. Murray CJED. Health Systems Performance Assessment: Debates, Methods and Empiricism. Geneva: World Health Organization; 2003.

25. Chatterji S. World Health Organisation's (WHO) Study on Global Ageing and Adult Health (SAGE). BMC Proc. 2013;7:S1. (Suppl 4 European Workshop on Health and Disability Surveilla.

26. Rice N, Robone S, Smith P. Analysis of the validity of the vignette approach to correct for heterogeneity in reporting health system responsiveness. Eur J Health Econ. 2011;12(2):141-162.

27. Li J, Assanangkornchai S, Lu L, et al. Can socio-economic differences explain low expectation of health services among HIV patients compared to non-HIV counterparts? Bmc Public Health. 2016;16:9.

28. Roder-Dewan S, Gage AD, Hirschhorn LR, et al. Expectations of healthcare quality: a cross-sectional study of internet users in 12 lowand middle-income countries. PLoS Med. 2019;16(8):e1002879. doi:10.1371/journal.pmed.1002879

29. Ewertzon M, Andershed B, Svensson E, Lützén K. Family members' expectation of the psychiatric healthcare professionals' approach towards them. J Psychiatr Ment Health Nurs. 2011;18(2):146-157. doi:10.1111/j.1365-2850.2010.01647.x

30. Musiat P, Goldstone P, Tarrier N. Understanding the acceptability of e-mental health-attitudes and expectations towards computerised self-help treatments for mental health problems. BMC Psychiatry. 2014;14:109. doi:10.1186/1471-244X-14-109

31. Korkeila J, Lehtinen V, Sohlman B, Tuori T. Patients' expectations from their psychiatric community care in Finland. Nordic $J$ Psychiatry. 1998;52(6):513-517. doi:10.1080/08039489850139300

32. Xie Z, Or C. Associations between Waiting Times, Service Times, and Patient Satisfaction in an Endocrinology Outpatient Department. Vol. 54:. A Time Study and Questionnaire Survey. Inquiry; 2017: 46958017739527.

33. Sun J, Lin Q, Zhao $P$, et al. Reducing waiting time and raising outpatient satisfaction in a Chinese public tertiary general hospitalan interrupted time series study. BMC Public Health. 2017;17(1):668.

34. The Canadian Institute for Health Information. Health care in Canada, 2012: a focus on wait times; 2012. Available from: https:// secure.cihi.ca/free products/HCIC2012-FullReport-ENweb.pdf.

35. Sun J, Hu GY, Ma J, et al. Consumer satisfaction with tertiary healthcare in China: findings from the 2015 China National Patient Survey. Int J Qual Health Care. 2017;1-9.

36. Makoul G, Zick A, Green M. An evidence-based perspective on greetings in medical encounters. Arch Intern Med. 2007;167(11):1172-1176.
37. Wallace LS, Cassada DC, Ergen WF, Goldman MH. Setting the stage: surgery patients' expectations for greetings during routine office visits. J Surg Res. 2009;157(1):91-95.

38. Karro J, Dent AW, Farish S. Patient perceptions of privacy infringements in an emergency department. Emerg Med Australas. 2005;17(2):117123.

39. Olsen JC, Sabin BR. Emergency department patient perceptions of privacy and confidentiality. J Emerg Med. 2003;25(3):329-333.

40. Xu Y, Shang X, Zhao H, et al. The characteristics of service efficiency and patient flow in heavy load outpatient service system. In: Chen J, Yamada Y, Ryoke M, Tang X, editors. Knowledge and Systems Sciences. KSS 2018. Communications in Computer and Information Science. 2018; Vol. 949:17-30. Singapore: Springer.

41. Blignault I, Ponzio V, Rong Y, Eisenbruch M. A qualitative study of barriers to mental health services utilisation among migrants from mainland China in south-east Sydney. Int J Soc Psychiatry. 2008;54 (2):180-190.

42. Conner-Spady BL, Johnston GH, Sanmartin C, McGurran JJ, Noseworthy TW; Gr SWREW. A bird can't fly on one wing: patient views on waiting for hip and knee replacement surgery. Health Expectations. 2007;10(2):108-116.

43. Knapp M, Funk M, Curran C, Prince M, Grigg M, McDaid D. Economic barriers to better mental health practice and policy. Health Policy Plan. 2006;21(3):157-170.

44. Que J, Shi L, Liu J, Sun Y, Bao Y, Lu L. The development of mental hospitals in China from 2002 to 2016. Chin J Psychiatry. 2019;52 (2):139-144.

45. WHO. Mental Health Atlas 2017. Geneva: World Health Organization; 2018.

46. Ma N, Yan J, Ma H, Yu X, Guo Y. Allocation of mental health facilities and psychiatric beds in China in 2010. Chin Mental Health J. 2012;26(12):885-889.

47. Dijkstra K, Pieterse M, Pruyn A. Physical environmental stimuli that turn healthcare facilities into healing environments through psychologically mediated effects: systematic review. J Adv Nurs. 2006;56 (2):166-181.

48. Association AP. Diagnostic and Statistical Manual of Mental Disorders. Fifth ed. Arlington, VA: American Psychiatric Publishing; 2013.

49. Xu XY, Li XM, Zhang JH, Wang WQ. Mental health-related stigma in China. Issues Ment Health Nurs. 2018;39(2):126-134.

50. Heim E, Kohrt BA, Koschorke M, Milenova M, Thronicroft G. Reducing mental health-related stigma in primary health care settings in low- and middle-income countries: a systematic review. Epidemiol Psychiat Sci. 2018;1-10.

51. Mann CE, Himelein MJ. Factors associated with stigmatization of persons with mental illness. Psychiatr Serv. 2004;55(2):185-187.

52. Huang ZFZ, Zhao X, Qiu T, Zhao Y, Cao X. Investigation on selfstigma and discrimination among HIV/AIDS patients in Suzhou. Jiangsu J Prev Med. 2015;26(02):10-12.

53. Yu Y, Zhou W, Liu ZW, Hu M, Tan ZH, Xiao SY. Gender differences in caregiving among a schizophrenia population. Psychol Res Behav Manage. 2019;12:7-13.
Patient Preference and Adherence

\section{Publish your work in this journal}

Patient Preference and Adherence is an international, peer-reviewed, open access journal that focusing on the growing importance of patient preference and adherence throughout the therapeutic continuum. Patient satisfaction, acceptability, quality of life, compliance, persistence and their role in developing new therapeutic modalities and compounds to optimize clinical outcomes for existing disease

\section{Dovepress}

states are major areas of interest for the journal. This journal has been accepted for indexing on PubMed Central. The manuscript management system is completely online and includes a very quick and fair peer-review system, which is all easy to use. Visit http:// www.dovepress.com/testimonials.php to read real quotes from published authors. 